\title{
Retrospective Analysis of Factors Associated with Long-Stay Hospitalizations in an Acute Psychiatric Ward
}

This article was published in the following Dove Press journal: Risk Management and Healthcare Policy

\section{Rosaria Di Lorenzo $\mathbb{D D}^{\prime}$ \\ Giulia Montardi (iD $)^{2}$ \\ Leda Panza ${ }^{3}$ \\ Cinzia Del Giovane ${ }^{4}$ \\ Serena Saraceni ${ }^{2}$ \\ Sergio Rovesti $\left.{ }^{5}\right)^{5}$ \\ Paola Ferri $\mathbb{1}^{6}$}

'Psychiatric Intensive Treatment Facility, Department of Mental Health and Drug Abuse, Az-USL Modena, Modena 4II22, Italy; ${ }^{2}$ School of Specialization in Psychiatry, University of Modena and Reggio Emilia, Modena 4I I24, Italy;

${ }^{3}$ School of Nursing, University of Modena and Reggio Emilia, Modena 4I I 24, Italy; ${ }^{4} \mathrm{Head}$ of Statistics and Methodology, Institute of Primary Health Care (BIHAM), Bern, Switzerland; ${ }^{5}$ General and Applied Hygiene, Department of Biomedical, Metabolic and Neural Sciences, Modena 4II25, Italy; ${ }^{6}$ Nursing, Department of Biomedical, Metabolic and Neural Sciences, Modena 4I I25, Italy
Correspondence: Rosaria Di Lorenzo Psychiatrist, Psychiatric Intensive Treatment Facility, Az-USL Modena, Modena 4 I I 22, Italy

Email r.dilorenzo@ausl.mo.it
Purpose: To evaluate the longest hospitalizations in an acute psychiatric ward [Service of Psychiatric Diagnosis and Treatment (SPDT)] and the related demographic, clinical and organizational variables to understand the factors that contribute to long-stay (LOS) phenomenon. The term "long stay" indicates clinical, social and organizational problems responsible for delayed discharges. In psychiatry, clinical severity, social dysfunction and/ or health-care system organization appear relevant factors in prolonging stays.

Patients and Methods: We divided all the SPDT hospitalizations from 1 January 2010 to 31 December 2015 into two groups based on the $97.5^{\text {th }}$ percentile of duration: $\leq 36$ day $(n=3254)$ and $>36$ day $(n=81)$ stays, in order to compare the two groups for the selected variables. Comparisons were made using Pearson's chi-square for categorical data and $t$-test for continuous variables, the correlation between the LOS, as a dependent variable, and the selected variables was analyzed in stepwise multiple linear regression and in multiple logistic regression models.

Results: The longest hospitalizations were significantly related to the diagnosis of "schizophrenia and other psychosis" (Pearson $\mathrm{Chi}^{2}=17.24 ; \mathrm{p}=0.045$ ), the presence of moderate and severe aggressiveness (Pearson $\left.\mathrm{chi}^{2}=29 ; \mathrm{p}=0.000\right)$, compulsory treatment (Pearson $\mathrm{Chi}^{2}=8.05$; $\mathrm{p}=0.005$ ), parenteral or other route administration of psycho-pharmacotherapy (Pearson $\left.\mathrm{Chi}^{2}=12.91 ; \mathrm{p}=0.007\right)$, poli-therapy (Pearson $\left.\mathrm{Chi}^{2}=6.40 ; \mathrm{p}=0.041\right)$, complex psychiatric activities (Pearson $\mathrm{Chi}^{2}=12.26 ; \mathrm{p}=0.002$ ) and rehabilitative programs (Pearson $\mathrm{Chi}^{2}=37.05$; $\mathrm{p}=0.000$ ) during the hospitalization and at discharge (Pearson $\mathrm{Chi}^{2}=29.89 ; \mathrm{p}=0.000$ ). Many demographic and clinical variables were statistically significantly correlated to the LOS at our multiple linear and logistic regression model.

Conclusion: In our sample, clinical illness severity and need for complex therapeutic and rehabilitative treatments were associated with prolonged psychiatric hospitalizations. Understanding this phenomenon can have not only economic but also clinical, ethical and social relevance.

Keywords: psychiatric long-stay, acute psychiatric ward, predictors of long-stay, illness severity

\section{Introduction}

In western countries, over the last three decades, the length of psychiatric hospitalizations has been drastically reduced in favor of community health care, ${ }^{1,2}$ but groups of patients have required frequent re-hospitalizations ("revolving door" phenomenon) ${ }^{3}$ or long stays in hospital ("new long-stay patients"). ${ }^{4}$ Due to the significant economic implications of this issue many efforts have been made not only to find which variables could predict the length of stay, but also how they mutually interact to impact on this phenomenon., ${ }^{5,6}$ 
One of the first articles highlighted that the phenomenon of "delayed discharges" accounted for 35\% of all discharges and was strictly related to social issues since delayed discharge patients represented the poorest section of the population. ${ }^{7}$ Other historical studies highlighted that, in psychiatry, "delayed discharges" ranged between $27 \%$ and $58 \%$, mainly due to patients' refusal of an assistance program and by patients' loneliness and social maladjustment. ${ }^{8}$ Successively, another Canadian study highlighted that lack of residential care and long waiting lists to get into a protected facility constituted the organizational reasons, whereas schizophrenia represented a clinical cause for delayed discharges in psychiatry. ${ }^{9}$ In a British study, poor living conditions, such as homelessness, significantly increased long-stays in psychiatric hospitals. ${ }^{10}$ Other more recent research on this phenomenon has highlighted that clinical severity and the lack of outpatient service programs were the most frequent reasons for "delayed discharges". ${ }^{11-13}$ Organic comorbidity and old age represented further risk factors for long psychiatric hospitalizations, according to other authors. ${ }^{14}$ In a recent European study, medical comorbidity was associated with increased length of stay in hospitalized psychiatric patients, after adjustment for several potential confounders. ${ }^{15}$ Other authors highlighted that hostility and manic excitement ${ }^{16}$ as well as aggressiveness during hospitalization represented risk factors for prolonged hospitalization. ${ }^{17}$ In a systematic review, Tulloch et al. $(2011)^{18}$ found a positive association between LOS and female gender, psychotic disorders and large hospital size. Regarding gender, a recent study hypothesized that shorter length of stay among male patients could be related to their more frequent substance abuse, which could favor to early discharge due to the difficulty in long therapeutic engagement. $^{19}$

Other studies focused on the differences between types of care organization: Bird et al., ${ }^{20}$ in a large sample of 2709 patients admitted to 80 adult psychiatry wards, did not find any difference in term of stay length when comparing critical organizational factors: patients in care treated by the same psychiatrist across both inpatient and outpatient settings stayed on average 7 fewer days than those treated by different psychiatrists, "suggesting factors aside from the organization of care and patient characteristics have an impact on length of stay". ${ }^{20}$

In Japan, where the length of hospitalizations often exceeds a period of one year, ${ }^{6}$ investigated the interaction between hospital organization variables and patients' demographic and clinical features. Interestingly, they found different interactions based on the type of ward (acute/emergency or general) and the seniority of psychiatrists: longer practice of the psychiatrist in acute/emergency ward led to longer duration of patient hospitalization, suggesting that length of stay depends on the service system rather than individual patient characteristics. ${ }^{6}$ Another Japanese study highlighted that patients living in regions with fewer home visits for psychiatric nursing care had significantly longer psychiatric stays. ${ }^{21}$ Also, in Canada, researchers observed that patients with a long wait for psychiatric consultation referral reported the longest duration of psychiatric hospitalizations, suggesting that the quality of health care organization can impact the length of stay. ${ }^{22}$ In this regard, other studies evidenced that alternatives to full-time hospitalizations, such as ambulatory care, part-time hospitalizations as well as full-time care integrated in the community, outside of inpatient settings (ie, hospitalizations at home, stays in therapeutic apartments, stays in specially trained families, crisis centers and rehabilitation centers), can represent benefits for reducing the length of full-time hospitalizations, in accordance with international recommendations for mental health care. $^{23}$

Up to now, differences in the length of psychiatric stay among countries have been reported and attributed to the range of treatment options available in the community as well as to cultural aspects regarding style of psychiatric care delivery. ${ }^{24}$ Studies on this topic are few and difficult to compare due to the variability of health-care organization systems, not only among different countries, but even within a country's local areas due to differences in clinical governance procedures and health organization policies and bed pressure. ${ }^{20}$

Nevertheless, a more recent study that evaluated the long-stay predictors in many European countries highlighted that "clinical severity and social dysfunction" appeared relevant factors despite different organizations and policies of the health-care system. ${ }^{25}$ Regarding treatment policies, a recent review did not highlight any consistent result regarding the possibility that community compulsory treatment can reduce readmission or length of inpatient stay. ${ }^{26}$

Regarding this international debate, other authors have outlined that after asylum closure, "virtual asylums" have been created in other places for new long-stay patients, who are defined in the UK national audit as those with admissions lasting between 3 and 6 months. ${ }^{27}$ 
In Italy, after asylum closure, the length of stay in both public and private psychiatric wards has been considerably reduced due to the hypothesis that the institution itself can represent a pathogenic factor, which can drastically worsen the course of psychiatric disorders. In accordance with the spirit of Italian Law 180 of 23 May 1978, which mandated the closure of psychiatric asylums, long psychiatric hospitalizations are considered the conditions which can induce regressive behavior, potentially worsening the course of psychiatric illnesses. In order to observe an Italian psychiatric context, many years after the aforementioned Law was implemented, we decided to analyze long stays in a psychiatric acute ward to deepen the potential critical issues related to this phenomenon.

\section{Aims}

In order to better understand the factors that contribute to long-stay phenomenon, we evaluated the correlation between the longest hospitalizations in an acute psychiatric ward and selected demographic, clinical and organizational variables, which, in accordance with the aforementioned literature can condition the length of stay.

\section{Patients and Methods}

This study was conducted in a 15-bed Italian public psychiatric ward, the so-called Service of Psychiatric Diagnosis and Treatment (SPDT), located in a general hospital of a town in the Italian Region of Emilia-Romagna, which received voluntary and involuntary patients affected by acute psychiatric diseases from a local population of 260,132 inhabitants up to June 2013 and subsequently from a local population of 511,782 inhabitants. Patients from other regions or towns can be admitted to this local ward but are subsequently transferred to the competent hospitals for specific geographic zone.

We retrospectively collected all hospitalizations recorded in the ward electronic database from 1 January 2010 to 31 December 2015, after having de-identified all patient data. More than one hospitalization per patient in the observation period was eligible for inclusion in the sample since the driver of analysis was all the hospitalizations and not the patients.

In accordance with literature, which defined "long stays" as the hospitalizations with a duration superior to $95^{\text {th }}$ percentile. ${ }^{28}$ In order to evaluate the longest ones, we divided all the SPDT hospitalizations in the observation period into two groups based on the $97.5^{\text {th }}$ percentile of duration: $\leq 36$ day $(\mathrm{n}=3254)$ and $>36$ day $(\mathrm{n}=81)$ stays.
We selected some demographic, clinical and organizational variables, which, in accordance with the aforementioned literature, could influence the duration of hospitalizations. Due to the retrospective design of this study, the choice of the variable was conditioned by their availability in the ward electronic database.

We collected the following:

1. Demographic variables (gender, nationality, age, place of residence).

2. Clinical variables [psychiatric and organic diagnosis according to local diagnostic system, International Classification of Diseases-9th revision-Clinical Modification (ICD-9-CM) ${ }^{29}$ mono- and polypharmacotherapy, drug administration route, compulsory and voluntary state of admission, extra-psychiatric medical activities (non-psychiatric consultations, clinical tests and therapy)].

3. Organizational variables [inpatient care activities/ problems: aggressive behavior (need for physical restraints and/or intervention of hospital security guards), rehabilitation programs, activation of community service network (Mental Health Service, Social Service, Drug Addiction Service, etc.), the discharge modalities].

After having labelled each variable with a number, we built an excel database in order to statistically analyze the data. We used standard statistics for descriptive analyses. Comparisons were made using Pearson's chi-square for categorical data and $t$-test for continuous variables, the correlation between the duration of hospitalizations, as a dependent variable, and the selected variables were analyzed in stepwise multiple linear regression, through backward selection estimation.

For a further evaluation of the potential determinants of the longest hospitalizations were analyzed by means of the correlation between the selected variables and the longest hospitalizations as dependent variable ( $\leq 36$ day hospitalizations $=0,>36$ day hospitalizations $=1$ ) in multivariate stepwise logistic regression model, through backward selection estimation. ${ }^{30}$ A probability (p-value) $<0.05$ was considered statistically significant. The statistical analysis was conducted by means of STATA-12 program (2011).

This study was conducted in accordance with the principles of the Declaration of Helsinki (World Medical Association Declaration of Helsinki, 1964) and good clinical practice. All information was collected after approval 
of the study by the Ethics Committee of Area Vasta Emilia Nord (Italy) (3577 Protocol, 262/17 Practice, 26-9-2017) and the local Mental Health Department and Drug Abuse (1917 Protocol, 20-10-2017).

\section{Results}

We recorded, from 1 January 2010 to 31 December 2015, 3335 hospitalizations for 2074 patients with a mean duration of $10.38 \pm 11.13$ standard deviation (SD) days and a median of 7 days. During the observation period, we collected our long-stay sample of 81 hospitalizations by 63 patients, with a duration above the $97.5^{\text {th }}$ percentile which represented $2.4 \%$ of all hospitalizations.

In Table 1, we report the comparison between the demographic variables related to the $\leq 36$ and $>36$ day hospitalizations. All demographic variables selected (age, gender, nationality and place of residence) were similar for both groups, without any statistically significant difference.

The comparison between the clinical variables of the $\leq 36$ and $>36$ day hospitalizations showed that psychiatric and rehabilitation activities, psycho-pharmacotherapy and routes of drug administration, aggressiveness and state of admission statistically significantly differed between the two groups (Table 2).

Regarding the clinical variables at discharge (Table 3), the most common psychiatric diagnosis was "schizophrenia and other psychoses", followed by "bipolar disorder", "personality disorders", "anxiety disorders", "alcohol, drugs and substance abuse" and other disorders, with a statistically significant difference between the two groups (Pearson $\left.\mathrm{Chi}^{2}=17.24 ; \mathrm{p}=0.045\right)$. In the $>36$ day group, the diagnosis "schizophrenia and other psychoses" was more frequent, whereas "anxiety disorders", "dementia and organic psychosis" and "acute stress reaction" were more common in the $\leq 36$ day hospitalizations (Table 3 ). The most frequent destination at discharge was "outpatient services", followed by "other psychiatric wards". The variable statistically which significantly differed between the two groups (Pearson $\mathrm{Chi}^{2}=13.02, \mathrm{p}=0.023$ ) was represented by "transfer to nonpsychiatric wards and/or protected facilities", more frequent discharge modality after $>36$ day hospitalizations, whereas "transfer to other psychiatric wards" was more frequent in the other group (Table 3).

Many demographic and clinical variables were statistically significantly correlated to the LOSs at our stepwise multiple regression linear model, as indicated in Table 4:

- age (coeff. 0.06), compulsory admission (coeff. 2.29), clinical interview with patient + caregivers (coeff. 4.32) or other professionals (coeff. 2.52), rehabilitation programs with staff of ward (coeff. 7.08) or other services (coeff. 2.11) during the hospitalization, moderate (coeff. 1.08) and severe (coeff. 4) aggressiveness

Table I Demographic Variables Related to Hospitalizations in SPDT from I/I/2010 to 3I/I2/20I5, Divided by the Duration

\begin{tabular}{|c|c|c|c|c|}
\hline $\begin{array}{l}\text { Demographic } \\
\text { Variables }\end{array}$ & $\begin{array}{l}\leq 36 \text { Days } \\
\text { Hospitalizations } \\
\mathrm{N}=3,254 \\
(97.57 \%)\end{array}$ & $\begin{array}{l}>36 \text { Days } \\
\text { Hospitalizations } \\
\mathrm{N}=8 \mathrm{I} \\
(2.43 \%)\end{array}$ & $\begin{array}{l}\text { Total } \\
\text { Hospitalizations } \\
\mathrm{N}=3,335 \\
(100 \%)\end{array}$ & $\begin{array}{l}\text { Statistical Test } \\
\text { Probability }\end{array}$ \\
\hline $\begin{array}{l}\text { Age }(m \pm S D) \\
\text { Years }\end{array}$ & $42.28 \pm 15.68$ & $41.02 \pm 16.34$ & $43.5 I \pm 16.38$ & $\begin{array}{l}t=0.71 \\
p=0.476\end{array}$ \\
\hline $\begin{array}{l}\text { Gender, n (\%) } \\
\text { Males } \\
\text { Females }\end{array}$ & $\begin{array}{l}1,845(57 \%) \\
1,409(43 \%)\end{array}$ & $\begin{array}{l}40(49 \%) \\
41(51 \%)\end{array}$ & $\begin{array}{l}1,885(55 \%) \\
1,450(45 \%)\end{array}$ & $\begin{array}{l}\text { Pearson } \mathrm{Chi}^{2}=1.72 \\
\mathrm{p}=0.189\end{array}$ \\
\hline $\begin{array}{l}\text { Nationality, n (\%) } \\
\text { Italian } \\
\text { Non-Italian }\end{array}$ & $\begin{array}{l}2,68 I(82 \%) \\
573(18 \%)\end{array}$ & $\begin{array}{l}64(79 \%) \\
17(21 \%)\end{array}$ & $\begin{array}{l}2,745(82 \%) \\
590(18 \%)\end{array}$ & $\begin{array}{l}\text { Pearson } \mathrm{Chi}^{2}=0.62 \\
\mathrm{p}=0.431\end{array}$ \\
\hline $\begin{array}{l}\text { Place of Residence, } \mathrm{n}(\%) \\
\text { Catchment area } \\
\text { Italy (outside the catchment area) } \\
\text { Non-Italian residence } \\
\text { Homeless }\end{array}$ & $\begin{array}{l}2,764(85 \%) \\
284(10 \%) \\
134(4 \%) \\
24(1 \%)\end{array}$ & $\begin{array}{l}69(85 \%) \\
3(4 \%) \\
7(10 \%) \\
1(1 \%)\end{array}$ & $\begin{array}{l}2,833(82 \%) \\
287(12 \%) \\
14 \mid(5 \%) \\
25(1 \%)\end{array}$ & Pearson $\mathrm{Chi}^{2}=6.39 \mathrm{p}=0.094$ \\
\hline
\end{tabular}


Table 2 Clinical Variables Related to Hospitalizations in SPDT from $1 / 1 / 2010$ to $31 / 12 / 2015$, Divided into Two Groups by the Duration

\begin{tabular}{|c|c|c|c|c|}
\hline Clinical Variables & $\begin{array}{l}\leq 36 \text { Days } \\
\text { Hospitalizations } \\
N=3,254 \\
(97.57 \%)\end{array}$ & $\begin{array}{l}>36 \text { Days } \\
\text { Hospitalizations } \\
\mathrm{N}=8 \mathrm{I} \\
(2.43 \%)\end{array}$ & $\begin{array}{l}\text { Total } \\
\text { Hospitalizations } \\
N=3,335 \\
(100 \%)\end{array}$ & $\begin{array}{l}\text { Statistical Test } \\
\text { Probability }\end{array}$ \\
\hline $\begin{array}{l}\text { Psychiatric Activities, } \mathrm{n}(\%) \\
\text { Clinical interview with patient alone } \\
\text { Clinical interview with patient + caregivers } \\
\text { Clinical interview with patient + caregivers + other professionals }\end{array}$ & $\begin{array}{l}\mathrm{I}, 433(45 \%) \\
\mathrm{I}, 424(45 \%) \\
337(10 \%)\end{array}$ & $\begin{array}{l}20(25 \%) \\
51(63 \%) \\
10(12 \%)\end{array}$ & $\begin{array}{l}\mathrm{I}, 453(44 \%) \\
\mathrm{I}, 475(46 \%) \\
347(10 \%)\end{array}$ & $\begin{array}{l}\text { Pearson } \mathrm{Chi}^{2}=12.26 \\
\mathrm{p}=0.002\end{array}$ \\
\hline $\begin{array}{l}\text { Organic Comorbidity, n (\%) } \\
\text { Present } \\
\text { Absent }\end{array}$ & $\begin{array}{l}669(21 \%) \\
2,585(79 \%)\end{array}$ & $\begin{array}{l}14(17 \%) \\
67(83 \%)\end{array}$ & $\begin{array}{l}683(20 \%) \\
2,652(80 \%)\end{array}$ & $\begin{array}{l}\text { Pearson } C h i^{2}=0.52 \\
p=0.471\end{array}$ \\
\hline $\begin{array}{l}\text { Rehabilitation Programs, } \mathrm{n}(\%) \\
\text { Absent } \\
\text { In the ward } \\
\text { With other services }\end{array}$ & $\begin{array}{l}2,006(61 \%) \\
125(4 \%) \\
1,123(35 \%)\end{array}$ & $\begin{array}{l}32(40 \%) \\
13(16 \%) \\
36(44 \%)\end{array}$ & $\begin{array}{l}2,038(61 \%) \\
138(4 \%) \\
1,159(35 \%)\end{array}$ & $\begin{array}{l}\text { Pearson } \mathrm{Chi}^{2}=37.05 \\
\mathrm{p}=0.000\end{array}$ \\
\hline $\begin{array}{l}\text { Extra-Psychiatric Clinical Activities, } n \text { (\%) } \\
\text { Present } \\
\text { Absent }\end{array}$ & $\begin{array}{l}\text { I,48I (46\%) } \\
\text { I,773 (54\%) }\end{array}$ & $\begin{array}{l}35(43 \%) \\
46(57 \%)\end{array}$ & $\begin{array}{l}1,516(45 \%) \\
1,819(55 \%)\end{array}$ & $\begin{array}{l}\text { Pearson } C i^{2}=0.17 \\
p=0.681\end{array}$ \\
\hline $\begin{array}{l}\text { Psycho-Pharmacotherapy, n (\%)* } \\
\text { No psycho-pharmacotherapy } \\
\text { Monotherapy } \\
\text { Politherapy }\end{array}$ & $\begin{array}{l}27(1 \%) \\
56 \mid(17 \%) \\
2,564(79 \%)\end{array}$ & $\begin{array}{l}0(0 \%) \\
6(7 \%) \\
73(90 \%)\end{array}$ & $\begin{array}{l}27(1 \%) \\
567(17 \%) \\
2,637(79 \%)\end{array}$ & $\begin{array}{l}\text { Pearson } \mathrm{Chi}^{2}=6.40 \\
\mathrm{p}=0.04 \mathrm{I}\end{array}$ \\
\hline $\begin{array}{l}\text { Routes of Drug Administration, } n \text { (\%)* } \\
\text { Oral } \\
\text { Parenteral/more than one route }\end{array}$ & $\begin{array}{l}2,362(73 \%) \\
806(25 \%)\end{array}$ & $\begin{array}{l}46(57 \%) \\
35(43 \%)\end{array}$ & $\begin{array}{l}2,408(72 \%) \\
84 \mathrm{I}(25 \%)\end{array}$ & $\begin{array}{l}\text { Pearson } \mathrm{Chi}^{2}=|2.9| \\
\mathrm{p}=0.000\end{array}$ \\
\hline $\begin{array}{l}\text { State of Admission, n (\%) } \\
\text { Voluntary } \\
\text { Compulsory }\end{array}$ & $\begin{array}{l}2,389(73 \%) \\
865(27 \%)\end{array}$ & $\begin{array}{l}48(59 \%) \\
33(41 \%)\end{array}$ & $\begin{array}{l}2,437(73 \%) \\
898(27 \%)\end{array}$ & $\begin{array}{l}\text { Pearson } C^{2} i^{2}=8.05 \\
p=0.005\end{array}$ \\
\hline $\begin{array}{l}\text { Aggressiveness, } \mathrm{n}(\%)^{* *} \\
\text { Absent } \\
\text { Moderate } \\
\text { Severe (with need for restraints and/or interventions of hospital } \\
\text { security guards) }\end{array}$ & $\begin{array}{l}2,300(71 \%) \\
653(20 \%) \\
254(8 \%)\end{array}$ & $\begin{array}{l}39(48 \%) \\
24(30 \%) \\
18(22 \%)\end{array}$ & $\begin{array}{l}2,339(70 \%) \\
677(20 \%) \\
272(8 \%)\end{array}$ & $\begin{array}{l}\text { Pearson } \mathrm{Chi}^{2}=29 \\
\mathrm{P}=0.000\end{array}$ \\
\hline
\end{tabular}

Notes: $* 3 \%$ data not available; $* 2 \%$ data not available.

manifested during hospitalization, poly-therapies (coeff. 2.4) administered by parenteral or more than one route (coeff. 2.41) and complex programs at discharge with one (coeff. 2.28) or more (coeff. 4.81) than one community outpatient service, with positive correlation;

- transfer to other psychiatric wards with negative correlation (coeff. -2.99 ).

At our multiple stepwise logistic regression model (Table 5), only four variables were statistically significantly related to the longest stays ( $>36$ day hospitalizations) as potential factors in prolonging stays, confirming the results of multiple linear regression model:

-"rehabilitation programs during the hospitalization" with ward staff (coeff.1.81);

-“aggressiveness during hospitalization", either moderate (coeff. 2.33) or severe (coeff. 3.44);

-"routes of drug administration", parenteral/more than one route" (coeff. 1.95);

-"therapeutic and rehabilitative programs at discharge" with more than one outpatient service (coeff. 5.3). 
Table 3 Clinical Variables Related to the Discharges from SPDT from I/I/2010 to $31 / 12 / 2015$, Divided by the Duration

\begin{tabular}{|c|c|c|c|c|}
\hline Clinical Variables & $\begin{array}{l}\leq 36 \text { Days } \\
\text { Hospitalizations } \\
N=3,254 \\
(97.57 \%)\end{array}$ & $\begin{array}{l}\text { >36 Days } \\
\text { Hospitalizations } \\
\mathrm{N}=8 \mathrm{I} \\
(2.43 \%)\end{array}$ & $\begin{array}{l}\text { Total } \\
\text { Hospitalizations } \\
\mathrm{N}=3,335 \\
(100 \%)\end{array}$ & $\begin{array}{l}\text { Statistical Test } \\
\text { Probability }\end{array}$ \\
\hline $\begin{array}{l}\text { Psychiatric Diagnosis (ICD-9-CM) at Discharge, } \mathrm{n}(\%)^{*} \\
\text { Schizophrenia and other psychotic disorders } \\
\text { Bipolar disorder } \\
\text { Anxiety disorders } \\
\text { Mental retardation } \\
\text { Dementia and organic psychosis } \\
\text { Personality disorders } \\
\text { Substance, drugs and alcohol abuse } \\
\text { Adjustment disorders } \\
\text { Other disorders } \\
\text { No psychiatric diagnosis }\end{array}$ & $\begin{array}{l}1,139(35 \%) \\
570(18 \%) \\
249(8 \%) \\
120(4 \%) \\
160(5 \%) \\
438(13 \%) \\
240(7 \%) \\
142(4 \%) \\
94(3 \%) \\
28(1 \%)\end{array}$ & $\begin{array}{l}42(52 \%) \\
14(17 \%) \\
\text { I (I\%) } \\
3(4 \%) \\
2(2 \%) \\
11(14 \%) \\
4(5 \%) \\
0(0 \%) \\
4(5 \%) \\
0(0 \%)\end{array}$ & $\begin{array}{l}\text { I,I8I (35\%) } \\
584(18 \%) \\
250(7 \%) \\
123(4 \%) \\
162(5 \%) \\
449(13 \%) \\
244(7 \%) \\
142(4 \%) \\
126(4 \%) \\
28(1 \%)\end{array}$ & $\begin{array}{l}\text { Pearson } \mathrm{Chi}^{2}=17.24 \\
\mathrm{p}=0.045\end{array}$ \\
\hline $\begin{array}{l}\text { Destination at Discharge, } \mathrm{n}(\%)^{* *} \\
\text { General practitioner } \\
\text { Community outpatient service } \\
\text { Transfer to other psychiatric wards } \\
\text { Transfer to non-psychiatric wards } \\
\text { Protected facilities } \\
\text { More than one outpatient community service }\end{array}$ & $\begin{array}{l}230(7 \%) \\
1,572(48 \%) \\
827(25 \%) \\
42(1 \%) \\
213(7 \%) \\
275(8 \%)\end{array}$ & $\begin{array}{l}8(10 \%) \\
40(49 \%) \\
10(12 \%) \\
2(2 \%) \\
11(14 \%) \\
7(9 \%)\end{array}$ & $\begin{array}{l}238(7 \%) \\
1,612(48 \%) \\
837(25 \%) \\
44(1 \%) \\
224(7 \%) \\
282(8 \%)\end{array}$ & $\begin{array}{l}\text { Pearson } \mathrm{Chi}^{2}=13.02 \\
\mathrm{p}=0.023\end{array}$ \\
\hline $\begin{array}{l}\text { Therapeutic and Rehabilitative Programs at Discharge, } n \text { (\%) } \\
\text { With practitioner } \\
\text { With one community outpatient service } \\
\text { With more than one community outpatient service }\end{array}$ & $\begin{array}{l}910(28 \%) \\
1,450(45 \%) \\
894(27 \%)\end{array}$ & $\begin{array}{l}7(9 \%) \\
31(38 \%) \\
43(53 \%)\end{array}$ & $\begin{array}{l}917(27 \%) \\
\text { I,48I (44\%) } \\
937(28 \%)\end{array}$ & $\begin{array}{l}\text { Pearson } \mathrm{Chi}^{2}=29.89 \\
\mathrm{P}=0.000\end{array}$ \\
\hline
\end{tabular}

Notes: $* 2 \%$ data not available; $* * 4 \%$ data not available.

\section{Discussion}

Our research was focused on the characteristics of the longest hospitalizations in an acute psychiatric ward, a phenomenon that is still only partially analyzed, although it represents a critical issue. This phenomenon is increasingly being studied in many Italian hospitals, ${ }^{31}$ but the available data on prolonged psychiatric hospitalizations are difficult to compare due to the differences among the health organizations of various regions or countries. As pointed out in other studies, the extrapolation and generalization of previous findings should take into account the specific characteristics of the regional/national mental health policies and cultures. ${ }^{6}$

In Italy, after Law $180,{ }^{32}$ subsequently included in Law 833 of 23/12/1978, which represented a dramatic change in psychiatric care, especially due to the complete abolition of psychiatric hospitals, the number of hospital beds for patients with psychiatric illnesses was reduced in order to avoid the risk of a chronic dependence on institutions. Currently in our country, hospitalizations in psychiatry are reserved for acute crisis and for short periods, whereas rehabilitation programs are planned by outpatient community services. ${ }^{33}$ In other countries, efforts are still being made to reinforce the cooperation between in- and outpatients services, with the aim to limit the LOSs in order to reduce inpatient resource utilization. ${ }^{19}$ Nevertheless, a recent Cochrane review which compared stays of less than vs more than 28 days in patients with severe mental illness concluded that there were no benefits from longer hospital stays in terms of readmission and other outcomes, and that short stays were associated with better social functioning. ${ }^{4}$

Our results highlighted that patients hospitalized for the longest periods did not differ from other patients for demographic characteristics (mean age, gender, nationality and place of residence). In our research, foreign and/or homeless patients were most often in the group with the longest hospitalizations, but without any statistically significant difference, suggesting that difficult environmental and social conditions might be one of the causes of 
Table 4 Variables Statistically Significantly Related to Dependent Variable, Length of Hospitalization (Stepwise Multiple Linear Regression)

\begin{tabular}{|c|c|c|c|c|}
\hline Variables & Coeff. & $\begin{array}{l}\text { Standard } \\
\text { Error }\end{array}$ & p-value & $\begin{array}{l}\text { Confidence Interval } \\
95 \%\end{array}$ \\
\hline Age & 0.06 & 0.013 & 0.000 & $0.03 ; 0.08$ \\
\hline Modality of Admission (Voluntary)* & & & & \\
\hline Compulsory & 2.29 & 0.42 & 0.000 & $1.46 ; 3.13$ \\
\hline Psychiatric Activities (Clinical Interview with Patient Alone)* & & & & \\
\hline Clinical interview with patient+caregivers & 4.32 & 0.40 & 0.000 & $3.52 ; 5.11$ \\
\hline Clinical interview with patient + caregivers + other professionals & 2.52 & 0.75 & 0.001 & $0.88 ; 3.79$ \\
\hline Rehabilitation Programs During the Hospitalization (Absent)* & & & & \\
\hline With staff of ward & 7.08 & 0.91 & 0.000 & $5.29 ; 8.86$ \\
\hline With staff of other services & 2.11 & 0.42 & 0.000 & $1.29 ; 2.94$ \\
\hline Aggressiveness During the Hospitalization (Absent)* & & & & \\
\hline Moderate & 1.08 & 0.51 & 0.035 & $0.07 ; 2.09$ \\
\hline Severe (with need for restraints and/or interventions of hospital security guards) & 4 & 0.7 & 0.000 & $2.63 ; 5.37$ \\
\hline Psycho-Pharmacotherapy (Monotherapy)* & & & & \\
\hline Polytherapy & 2.4 & 0.49 & 0.000 & $1.44 ; 3.36$ \\
\hline Routes of Drug Administration (Oral)* & & & & \\
\hline Parenteral/more than one route & 2.41 & 0.44 & 0.000 & $1.55 ; 3.27$ \\
\hline Destination at Discharge (General Practitioner)* & & & & \\
\hline Transfer to other psychiatric wards & -2.99 & 0.77 & 0.000 & $-4.5 I ;-1.46$ \\
\hline Therapeutic and Rehabilitative Programs at Discharge (With Practitioner)* & & & & \\
\hline With one community outpatient service & 2.28 & 0.49 & 0.000 & $1.32 ; 3.23$ \\
\hline With more than one community outpatient service & 4.81 & 0.55 & 0.000 & $3.72 ; 5.89$ \\
\hline
\end{tabular}

Note: * Reference category.

Table 5 Variables Statistically Significantly Related to the Longest Hospitalizations (Stepwise Multiple Logistic Regression)

\begin{tabular}{|c|c|c|c|c|}
\hline Variables & Coeff. & $\begin{array}{l}\text { Standard } \\
\text { Error }\end{array}$ & p-value & Confidence Interval 95\% \\
\hline $\begin{array}{l}\text { Rehabilitation Programs During the Hospitalization (Absent)* } \\
\text { With ward staff }\end{array}$ & 1.81 & 0.45 & 0.016 & $1.12 ; 2.95$ \\
\hline $\begin{array}{l}\text { Aggressiveness During the Hospitalization (Absent)* } \\
\text { Moderate } \\
\text { Severe (with need of restraints and/or interventions of hospital security guards) }\end{array}$ & $\begin{array}{l}2.33 \\
3.44\end{array}$ & $\begin{array}{l}0.58 \\
1.05\end{array}$ & $\begin{array}{l}0.005 \\
0.000\end{array}$ & $\begin{array}{l}1.25 ; 3.63 \\
1.88 ; 6.26\end{array}$ \\
\hline $\begin{array}{l}\text { Routes of Drug Administration (Oral)* } \\
\text { Parenteral/more than one route }\end{array}$ & 1.95 & 0.46 & 0.005 & $1.22 ; 3.11$ \\
\hline $\begin{array}{l}\text { Therapeutic and Rehabilitative Programs at Discharge (With Practitioner)* } \\
\text { With more than one community outpatient service }\end{array}$ & 5.3 & 2.61 & 0.001 & $2.01 ; 13.93$ \\
\hline
\end{tabular}

Note: * Reference category.

psychiatric-delayed discharges, as the first studies on this phenomenon highlighted. ${ }^{7,10,13}$ Nevertheless, we have to put in evidence that, in our study, this variable did not show any significant correlation with the LOSs. Among demographic variables, apart from the above-reported data, only increased age showed a significant, positive but weak, correlation with the LOSs, confirming only in part the results of other authors. ${ }^{14}$ All our other results 
indicate that risk factors for long stays were mainly represented by clinical and organizational variables. The pathologies in the group of patients with the longest hospitalizations were serious and potentially disabling, such as schizophrenia and other psychotic spectrum disorders, in accordance with data reported in the literature. ${ }^{9,34}$

The factors which conditioned the LOS were constituted by complex psychiatric activities during hospitalization and at discharge involving of family members or caregivers, pharmacological therapies administered by multiple routes, intensive rehabilitation programs provided by ward staff and/or other services, and both mild and severe aggressive behavior. Altogether, these clinical and organizational variables indicate that patients who remain hospitalized for a very long time are characterized by multiple care needs closely related to the severity of psychiatric pathologies and not to organic comorbidities or social disadvantage. As suggested by other Authors, in investigating long-stay phenomenon, special attention should be given to indicators of illness severity, represented by functioning scale scores, length and number of previous hospitalizations, employment, marital and housings status. $^{18}$

In particular, among the longest hospitalizations, the presence of aggressiveness, either moderate or severe, and the need for complex therapeutic treatment during the hospitalizations were the statistically significant conditioning factors of hospitalization prolongation, in line with the results of other authors who highlighted that violence during the hospitalization as well as high number of medical conditions requiring medication could prolong the period of stays. $^{35}$

Aggressiveness, which was particularly frequent among the patients with the longest hospitalizations in our and other studies, ${ }^{14,18}$ could represent a severe and acute symptom of many psychiatric disorders, often responsible for hospital admission, frequent readmissions ${ }^{3}$ and, according to other research, ${ }^{36}$ for the frequent aggressions towards staff, in particular nurses, ${ }^{37}$ in a psychiatric setting. The observation of serious and potentially dangerous aggressive behavior among patients with long-term hospitalizations corresponded with the data of the higher frequency of compulsory treatment in this group, which suggests the lack of illness awareness and behavior control among these patients. This result indirectly confirms that compulsory treatment does not reduce length of inpatient stay, ${ }^{26}$ but it can represent an indicator of illness severity in psychiatry and a potential predictor of the long stay, as some Italian authors highlighted. ${ }^{38,39}$ We can hypothesize that aggressiveness itself could justify the difficulty in discharging patients, especially when it starts a sort of vicious cycle of aggressive escalation, that can trigger pathological dependence of patients on the institution.

Regarding the discharge modalities, as some authors have already highlighted, $3,40,41$ our patients with the longest hospitalizations needed to be sent to protected facilities for implementing complex programs carried out by more than one community service, probably due to the severity of clinical conditions and functioning abilities.

The variables significantly related to the length of psychiatric hospitalizations indicate that the severity of symptoms, which often leads to difficulties in socio-relational functioning and adherence to care, can also lead to the risk of extended hospitalizations, requiring the involvement of a wide range of therapeutic, care and rehabilitation programs. Therefore, we hypothesize that, for preventing the long-stay phenomenon, the same Intensive Case Management provided by mental health service for satisfying the unique combination of health and social care needs of people with severe mental illness, as recently highlighted by a Cochrane review, ${ }^{42}$ could be effective.

In accordance with other authors, our results show that length of stay is "multifactorially" determined. More studies evaluating factors that lengthen hospital stay are needed to implement more appropriate and tailored treatments in psychiatric services. ${ }^{24,41}$ Understanding this phenomenon has not only organizational and economic but also clinical, ethical and social relevance, as evidenced by most authors. ${ }^{43}$ The identification of factors associated with long hospitalization makes it possible to organize more appropriate therapeutic programs, reducing the economic burden on health care and, at the same time, the risk of psychological and physical complications for patients.

\section{Limitations and Strengths}

This study has a number of limitations. The retrospective methodology did not allow us to infer any causality and needs prospective research to be confirmed. The selection of variables was conditioned by their database availability, due to the retrospective design, and were not chosen according to a risk model based on a prospective research design. Future research on this topic, based on the results of this and other studies, will be able to build a reliable theoretical model, that will drive the search. Moreover, its results cannot be extrapolated to other psychiatric services. In particular, the generalizability of their findings is 
limited due to the important role that context plays in determining length-of-stay in psychiatric wards in Italy.

Nevertheless, this study analyzed many variables in a large sample, for a sufficiently long observation period, providing data from Italian psychiatric services to add to the international body of literature, suggesting risk factors that could potentially be addressed with the right kind of outpatient programs.

Further prospective studies, which takes into consideration the correlations highlighted by this research, could deepen our knowledge of the long-stay phenomenon.

\section{Conclusions}

We conclude by suggesting that the most prolonged hospitalizations in an acute psychiatric ward can be related to clinical features of illness severity as well as maladjustment or social drift condition, which, in turn, could be induced by serious and chronic mental illnesses.

More tailored health community programs aimed at reducing this new chronicity could permit us to improve the quality of life of these patients, reducing, at the same time, the economic and social consequences of still unresolved pathologies.

Finally, we can conclude by indicating that health treatments and policies, in order to provide a real economic return and quality of life in the long term, should be mainly addressed to the needs of each patient. We hope to have deepened the understanding of the determinants of long psychiatric stay, contributing to the appropriateness of treatments and care in psychiatry.

\section{Disclosure}

The authors report no actual or potential conflicts of interest.

\section{References}

1. Furlan PM, Zuffranieri M, Stanga F, Ostacoli L, Patta J, Picci RL. Four-year follow-up of long-stay patients settled in the community after closure of Italy's psychiatric hospitals. Psychiatr Serv. 2009;60 (9):1198-1202. doi:10.1176/ps.2009.60.9.1198

2. Preti A, Rucci P, Gigantesco A, for PROGRES-Acute Group, et al. Patterns of care in patients discharged from acute psychiatric inpatient facilities: a national survey in Italy. Soc Psychiatry Psychiatr Epidemiol. 2009;44(9):767-776. doi:10.1007/s00127-009-0498-2.

3. Di Lorenzo R, Sagona M, Landi G, Martire L, Piemonte C, Del Giovane C. The revolving door phenomenon in an italian acute psychiatric ward: a 5-year retrospective analysis of the potential risk factors. J Nerv Ment Dis. 2016;204(9):686-692. doi:10.1097/ NMD.0000000000000540

4. Babalola O, Gormez V, Alwan NA, Johnstone P, Sampson S. Length of hospitalisation for people with severe mental illness. Cochrane Database Syst Rev. 2014;1:CD000384.
5. Johnstone P, Zolese G. Length of hospitalisation for people with severe mental illness. Cochrane Database Syst Rev. 2000;2: CD000384.

6. Badriah F, Abe T, Nabeshima Y, Ikeda K, Kuroda K, Hagihara A. Predicting the length of hospital stay of psychiatry patients using signal detection analysis. Psychiatry Res. 2013;210(3):1211-1218. doi:10.1016/j.psychres.2013.09.019

7. Barrette PA. 1,005 delayed days: a study of adult psychiatric discharge. Hosp Community Psychiatry. 1981;32(4):266-268. doi:10.1176/ps.32.4.266

8. Zeldow PB, Taub HA. Evaluating psychiatric discharge and aftercare in a VA medical center. Hosp Community Psychiatry. 1981;32 (1):57-58. doi:10.1176/ps.32.1.57

9. Kelly A, Watson D, Raboud J, Bilsker D. Factors in delays in discharge from acute-care psychiatry. Can J Psychiatry. 1998;43 (5):496-501. doi:10.1177/070674379804300508

10. Koffman J, Fulop NJ. Homelessness and the use of acute psychiatric beds: findings from a one-day survey of adult acute and low-level secure psychiatric patients in North and South Thames regions. Health Soc Care Community. 1999;7(2):140-147. doi:10.1046/ j.1365-2524.1999.00156.x

11. Tulloch AD, Fearon P, David AS. Timing, prevalence, determinants and outcomes of homelessness among patients admitted to acute psychiatric wards. Soc Psychiatry Psychiatr Epidemiol. 2012;47 (7):1181-1191. doi:10.1007/s00127-011-0414-4

12. Tulloch AD, Khondoker MR, Fearon P, David AS. Associations of homelessness and residential mobility with length of stay after acute psychiatric admission. BMC Psychiatry. 2012;12:121. doi:10.1186/ 1471-244X-12-121

13. Russolillo A, Moniruzzaman A, Parpouchi M, Currie LB, Somers JM. A 10-year retrospective analysis of hospital admissions and length of stay among a cohort of homeless adults in Vancouver, Canada. BMC Health Serv Res. 2016;16:60. doi:10.1186/s12913-0161316-7

14. Lewis R, Glasby J. Delayed discharge from mental health hospitals: results of an English postal survey. Health Soc Care Community. 2006;14(3):225-230. doi:10.1111/j.1365-2524.2006.00614.x

15. Rodrigues-Silva N, Ribeiro L. Impact of medical comorbidity in psychiatric inpatient length of stay. J Ment Health. 2017;1-5. doi:10.1080/09638237.2017.1340605

16. Warnke I, Rössler W, Herwig U. Does psychopathology at admission predict the length of inpatient stay in psychiatry? Implications for financing psychiatric services. BMC Psychiatry. 2011;11:120. doi:10.1186/1471-244X-11-120

17. Gigantesco A, de Girolamo G, Santone G, Miglio R, Picardi A, for PROGRES-Acute Group. Long-stay in short-stay inpatient facilities: risk factors and barriers to discharge. BMC Public Health. 2009;22 (9):306. doi:10.1186/1471-2458-9-306

18. Tulloch AD, Fearon P, David AS. Length of stay of general psychiatric inpatients in the United States: systematic review. Adm Policy Ment Health. 2011;38(3):155-168. doi:10.1007/s10488-010-0310-3

19. Wullschleger A, Wosniok W, Timm J, Heinze M. Challenges and perspectives in bridging in- and outpatient sectors: the implementation of two alternative models of care and their effect on the average length of stay. Front Psychiatry. 2017;8:196. doi:10.3389/fpsyt.2017.00196

20. Bird VJ, Giacco D, Nicaise P, et al. In-patient treatment in functional and sectorised care: patient satisfaction and length of stay. $\mathrm{Br}$ J Psychiatry. 2018;212(2):81-87. doi:10.1192/bjp.2017.20

21. Niimura J, Nakanishi M, Yamasaki S, Nishida A. Regional supply of outreach service and length of stay in psychiatric hospital among patients with schizophrenia: national case mix data analysis in Japan. Psychiatry Res. 2017;258:295-298. doi:10.1016/j.psychres.2017.08.067

22. Sockalingam S, Alzahrani A, Meaney C, et al. Time to consultation-liaison psychiatry service referral as a predictor of length of stay. Psychosomatics. 2016;57(3):264-272. doi:10.1016/j. psym.2016.01.005 
23. Gandré C, Gervaix J, Thillard J, Macé JM, Roelandt JL, Chevreul K. The development of psychiatric services providing an alternative to full-time hospitalization is associated with shorter length of stay in French public psychiatry. Int J Environ Res Public Health. 2017;14:3. doi:10.3390/ijerph14030325

24. Baeza FL, da Rocha NS, Fleck MP. Predictors of length of stay in an acute psychiatric inpatient facility in a general hospital: a prospective study. Braz J Psychiatry. 2018;40(1):89-96. doi:10.1590/1516-44462016-2155

25. Dimitri G, Giacco D, Bauer M, et al. Predictors of length of stay in psychiatric inpatient units: does their effect vary across countries? Eur Psychiatry. 2018;48:6-12. doi:10.1016/j.eurpsy.2017.11.001

26. Barnett P, Matthews H, Lloyd-Evans B, Mackay E, Pilling S, Johnson S. Compulsory community treatment to reduce readmission to hospital and increase engagement with community care in people with mental illness: a systematic review and meta-analysis. Lancet Psychiatry. 2018;5 (12):1013-1022. doi:10.1016/S2215-0366(18)30382-1

27. Sharma A, Dunn W, O'Toole C, Kennedy HG. The virtual institution: cross-sectional length of stay in general adult and forensic psychiatry beds. Int J Ment Health Syst. 2015;9:25. doi:10.1186/s13033-0150017-7

28. Tukey JW. Explorating Data Analysis. Boston: Addison-Wesley; 1977.

29. Ministry of Labour, Health and Social Policy. International Classification of Diseases-9th Revision-Clinical Modification. Roma, Italy: Istituto Poligrafico e Zecca dello Stato; 2008.

30. Berk R. Regression Analysis: A Constructive Critique. Thousand Oaks, CA: Sage Publications; 2004.

31. Mongardi M, Di Ruscio E, Vizioli M, et al. Il fenomeno delle dimissioni ospedaliere ritardate nella regione Emilia-Romagna. Mecosan. 2013;86:65-78.

32. Burti L, Benson PR. Psychiatric reform in Italy: developments since 1978. Int J Law Psychiatry. 1996;19(3-4):373-390. doi:10.1016/ S0160-2527(96)80008-2

33. de Girolamo G, Polidori G, Morosini P, et al. Prevalence of common mental disorders in Italy: results from the European Study of the Epidemiology of Mental Disorders (ESEMeD). Soc Psychiatry Psychiatr Epidemiol. 2006;41(11):853-861. doi:10.1007/s00127-0060097-4
34. Di Lorenzo R, Formicola V, Carra E, Piemonte C, Ferri P. Risk factors for long-stay in an Italian acute psychiatric ward: a 7-year retrospective analysis. J Nurs Educ Pract. 2014;4:68-80.

35. Cheng JE, Shumway M, Leary M, Mangurian CV. Patient factors associated with extended length of stay in the psychiatric inpatient units of a large urban county hospital. Community Ment Health J. 2016;52(6):658-661. doi:10.1007/s10597-015-9912-2

36. Ferri P, Silvestri M, Artoni C, Di Lorenzo R. Workplace violence in different settings and among various health professionals in an Italian general hospital: a cross-sectional study. Psychol Res Behav Manag. 2016;9:263-275. doi:10.2147/PRBM.S114870

37. Ferri P, Reggiani F, Di Lorenzo R. Aggressive behavior toward nursing staff in three different health care settings. [corrected]. Prof Inferm. 2011;64(3):143-150.

38. Ielmini M, Poloni N, Caselli I, Gasparini A, Pagani R, Callegari C. Compulsory versus voluntary admission in psychiatry: an observational study. Minerva Psichiatr. 2018;59(3):124-134.

39. Di Lorenzo R, Vecchi L, Artoni C, Mongelli F, Ferri P. Demographic and clinical characteristics of patients involuntarily hospitalized in an italian psychiatric ward: a 1-year retrospective analysis. Acta Biomedica. 2018;89(6-8):17-28. doi:10.23750/abm. v89i6-S.7392

40. Glasby J, Lester H. Delayed hospital discharge and mental health: the policy implication of recent research. Soc Policy Admin. 2004;38 (7):744-757.

41. Newman L, Harris V, Evans LJ, Beck A. Factors associated with length of stay in psychiatric inpatient services in London, UK. Psychiatr Q. 2018;89(1):33-43.

42. Dieterich M, Irving CB, Bergman H, Khokhar MA, Park B, Marshall M. Intensive case management for severe mental illness. Cochrane Database Syst Rev. 2017;1:CD007906.

43. Swidler RN, Seastrum T, Shelton W. Difficult hospital inpatient discharge decisions: ethical, legal and clinical practice issues. $\mathrm{Am}$ J Bioeth. 2007;7(3):23-28. doi:10.1080/15265160601171739
Risk Management and Healthcare Policy

\section{Publish your work in this journal}

Risk Management and Healthcare Policy is an international, peerreviewed, open access journal focusing on all aspects of public health, policy, and preventative measures to promote good health and improve morbidity and mortality in the population. The journal welcomes submitted papers covering original research, basic science, clinical \& epidemiological studies, reviews and evaluations, guidelines, expert opinion and commentary, case reports and extended reports. The manuscript management system is completely online and includes a very quick and fair peer-review system, which is all easy to use. Visit http://www.dovepress.com/testimonials.php to read real quotes from published authors. 